\title{
The impact of moderate- and high-intensity exercise on microbiota population and short-chain fatty acid production in the cecum of
}

\section{rats}

\author{
Andreanyta Meliala $^{*}$ (D), Paramita Narwidina² (D), Hera Nirwati ${ }^{3}$ (D), Titik Nuryastuti ${ }^{3}$ (D), Muhammad Kamil ${ }^{4}$, \\ Laode Ardiansyah ${ }^{4}$, Arso Pranindyo ${ }^{4}$ \\ ${ }^{1}$ Department of Physiology, Faculty of Medicine, Public Health and Nursing, Gadjah Mada University, Yogyakarta, Indonesia. \\ ${ }^{2}$ Clinical Nutrition Research Group, Yogyakarta, Indonesia. \\ ${ }^{3}$ Departement of Microbiology, Faculty of Medicine, Public Health and Nursing, Gadjah Mada University, Yogyakarta, Indonesia. \\ ${ }^{4}$ Master Program of Department of Physiology, Faculty of Medicine, Public Health and Nursing, Gadjah Mada University, Yogyakarta, Indonesia.
}

\begin{tabular}{l}
\hline ARTICLE INFO \\
\hline Received on: $19 / 12 / 2020$ \\
Accepted on: $20 / 05 / 2021$ \\
Available online: 05/08/2021 \\
\\
\hline Key words: \\
Gut microbiota, exercise, \\
Lactobacillus spp., \\
Escherichia coli, short-chain \\
fatty acid.
\end{tabular}

\begin{abstract}
The body's immunity can be increased by physical exercise. High-intensity physical exercise (HIPE) can disturb the body's digestive system and cause an imbalance of the microbiome population between pathogenic and nonpathogenic bacteria. This posttest-only control group study was conducted on 18 male Wistar rats which were divided into three groups $(n=6)$ : (1) control (nonexercised); (2) moderate-intensity physical exercise (MIPE) (30 minutes at $55 \% \mathrm{VO}_{2}$ max/day, 5 days per week); and (3) high-intensity physical exercise (HIPE) (30 minutes at $85 \% \mathrm{VO}_{2}$ max/day, 5 days per week). After 5 weeks, subjects' cecum was isolated from the gut and colony-forming units were counted for the total lactic acid bacteria, Lactobacillus spp., and Escherichia coli. Microbiological analysis of the cecal contents indicated that, in comparisons between the control, the MIPE, and the HIPE groups, there were no statistically significant differences between the bacterial groups except for $E$. coli between the MIPE and HIPE groups $(p<0.05)$. Additionally, the MIPE group showed a significantly higher acetate and propionic acid concentration compared to the HIPE and control groups $(p<0.05)$. Moderate but not high-intensity exercise may contribute to better well-being of the microbiota environment as shown by the significantly higher acetic and propionic acid production.
\end{abstract}

\section{INTRODUCTION}

The body's defenses are protection against perceived harm to the body from the outside environment such as bacteria, viruses, fungi, and protozoa (Hart, 1990). When the body's resistance is weakened, the infective agent will more easily penetrate the body's defenses and cause disease. One way to increase the body's immunity is by doing physical exercise. Moderate physical activity is known to help the process of transferring glucose into muscle cells so that it can be easily used by the body. In certain disease conditions such as diabetes, physical exercise will increase the level of insulin receptors, glucose transporter proteins, and

\footnotetext{
*Corresponding Author

Andreanyta Meliala, Department of Physiology, Faculty of Medicine, Public Health and Nursing, Gadjah Mada University, Yogyakarta, Indonesia.E-mail: a_meliala@ugm.ac.id
}

the level of insulin sensitivity (Sohail et al., 2019; Yousefi and Bakhtiyari, 2017).

Physical exercise is very important in increasing the body's metabolism and immune system, by reducing stress and maintaining the balance of the intestinal microflora. Microflora can live and develop in the human body by utilizing the intestines, including the cecum which is the proximal part of the large intestine. The distribution of the intestinal microbiota varies according to the location within the intestines (Sekirov et al., 2010). Research showed that the presence of bacteria increases from the stomach to the large intestines, where the number of bacteria is $10^{1}-10^{3}$ cells/g in the stomach and duodenum, with $10^{4}-10^{7}$ cells/g in the jejunum and ileum, while as many as $10^{11}-10^{12}$ cells/g are found in the colon (Finegold et al., 1983; O'Hara and Shanahan, 2006).

The undigested carbohydrate compounds in the small intestine will ferment in the large intestine into short-chain fatty acids (SCFAs), including acetate, propionate, and butyrate 
(Russell et al., 2013). The presence of SCFA is very helpful in reducing the risk of developing several diseases, including irritable bowel syndrome, cardiovascular disease, and cancer (Hijova and Chmelarova, 2007). In general, SCFAs play a role in lowering intestinal $\mathrm{pH}$, which can inhibit the growth of pathogenic bacteria, improve blood flow through the colonic blood vessels, increase the proliferation of epithelial cells, and induce peristaltic activity, which later will decrease transit times in the colon (Picard, 2005).

The more positive or benign the bacteria in the intestines, the more the protection for the body against diseases. Based on research conducted by Matsumoto et al. (2008), physical exercise can alter the microflora composition and increase the butyrate concentration in mouse cecum, where changes in microflora composition occur between the mice given physical exercise and the group of mice not given physical exercise. Results showed that mice with physical exercise had concentrations of acetate, propionate, and butyrate in the cecum which were significantly higher compared to the group of mice that were not given physical exercise.

Moderate-intensity physical exercise (MIPE) can be the external agent that can change the quality of the microflora in the intestines, while physical exercise with high intensity can disturb the body's digestive system such as causing reflexes in the stomach and disorders of the intestines. These are caused by an imbalance in the number of microflora, which will contribute to decreased bodily functions (Nieman and Wentz, 2019). Thus, High-intensity physical exercise (HIPE)high-intensity can lead to dysbiosis (population imbalance between pathogenic and nonpathogenic bacteria), so that the body is more susceptible to infection and prone to disease. Based on this description, it is known that physical exercise with a certain intensity is important in maintaining the balance of the intestinal microflora as one of the defensive lines of the immune system. The present study has provided new light on the significance of low- and moderate-intensity physical activity in improving the efficiency of the immune system"s protection across various pathways, specifically the digestive system, by optimizing a healthy microflora population and suppressing the growth of harmful microflora.

\section{MATERIALS AND METHODS}

\section{Animals and diet}

This posttest-only control study involved $18(n=18)$ healthy male Wistar rats (3-4 months; 200-300 g) from Pharmacy Laboratory, Universitas Gadjah Mada. Maintained in climatecontrolled cages, the ambient temperature ranged from $24^{\circ} \mathrm{C}$ to $34^{\circ} \mathrm{C}$ and the relative humidity was approximately $70 \%-100 \%$ with a light cycle of 12 hours on/12 hours off. After 7 days of acclimatization, the rats were randomly divided into 3 groups: control group ( $n=6$ ), MIPE group (MIPE, $n=6$ ), and (HIPE, $n=6$ ). Equipment for the maintenance of experimental animals included animal pens, feed and drinking containers, masks, and gloves. Equipment for physical exercise of the experimental animals used a treadmill made for rats and a stopwatch. Gas chromatography was used for checking levels of SCFA. AD2 standard feed and sterile distilled water were given ad libitum as the food and drink for the experimental animals. Materials for colon tissue isolation included $0.9 \% \mathrm{NaCl}$, distilled water, MRS agar, and agar Chromocult ${ }^{\circledR}$ tryptone bile x-glucuronide (TBX).
All of the research procedures were done with the approval of the institutional review board and with proper supervision under protocol number 00089/04/LPPT/VIII/2017.

\section{Exercise training}

To minimize natural stress, rats were accustomed to the treadmill tools which were shared with the sedentary (control) group. Meanwhile, the MIPE group did 30 minutes running every day 5 times per week for 5 weeks, with $\mathrm{VO}_{2} \max 55 \%$, and the HIPE group did 30 minutes of daily running session 5 times per week for 5 weeks, $\mathrm{VO}_{2} \max 85 \%$. All rats were given treadmill adaptation for 7 days with the following procedure:

Day 1. (i) Run the treadmill at the lowest speed for 5 minutes. (ii) Give attention to the rats while running, and correct the direction if it is wrong. (iii) Turn off the tool and return the rats to the cage, and give it access to drink ad libitum.

Days 2 and 3. (i) Run the treadmill at the lowest speed for 20 minutes. (ii) Start the foot shock if the rats stop running. (iii) Remove and mark the rats that do not want to run and are exposed to foot shock more than five times in the first 10 minutes. (iv) Turn off the appliance and return the mouse to the cage, and give it access to ad libitum

Days 4-7. (i) Repeat procedure of day 3. (ii) If at the end of day 7 , the rats do not want to run and are exposed to foot shock more than five times in the first 10 minutes, mark and separate them as control rats.

Rats that have passed the acclimatization procedure were given a physical exercise protocol to estimate the $\mathrm{VO}_{2}$ max level modified methods (Brooks and White, 1979) as follows: (1) $10 \%$ treadmill slope (approx. 180). (2) The mouse is placed on the treadmill. (3) Run the treadmill at the lowest speed and increase the speed by approximately $5 \mathrm{~m} /$ minute until the rats are tired. (4) Note the time the mouse has traveled until it is tired and the last speed it can pass. Rat fatigue can be tested when mice that are no longer willing to run or are exposed to a foot shock $>3 \times$ at the same speed are removed and laid on their backs. If the rats continue trying to turn over or get up again, it means the mouse is not tired and the procedure must be repeated the next day. (5) If it meets the criteria for fatigue, $\mathrm{VO}_{2}$ max level can be calculated using the formula:

$$
\begin{aligned}
& \text { V02 max Index }=\left[\text { speed of level running }\left(\frac{m}{\text { minute }}\right)\right] \\
& \times[\text { the } \operatorname{slope}(\%) \times 100] \times[\text { body weight }(\mathrm{kg})]
\end{aligned}
$$

The slope is set at $10 \%$ or (180) unchanged so the dose is speed-dependent; if the rats are unable to run or cannot keep up with the treadmill speed so that the $\mathrm{VO}_{2}$ max index cannot be calculated, then the rats are included in the control group. After estimating $\mathrm{VO}_{2} \max$, rats were given treadmill physical exercise treatment for 5 weeks. Treadmill physical exercise is performed at high intensity and moderate intensity with the following procedure: the treadmill slope at 100 (approx. 180) does not change during the study, but for the rats on the treadmill, warm-up is done for 5 minutes at a speed of $20 \%$ of the maximum speed of each rat. This training period is done for 30 minutes at a speed of $55 \%$ and $85 \%$ of the maximum speed of each rat according to the group. The treadmill physical exercise is done five times per week for 5 weeks. 


\section{Cecum sample preparation}

After 5 weeks of treatment, the subjects were euthanized using ketamine hydrochloride, $80 \mathrm{mg} / \mathrm{kg}$ intraperitoneal, and were decapitated. The cecum was collected from the subjects immediately after the decapitation and then the subjects were disposed of in sterile glass containers. The sample of fresh cecal content was immediately transported to the laboratory and under the frozen condition was prepared. For direct culture detection methods, a cecum suspension of $1 \mathrm{~g}$ of pooled sample vortexed in $9 \mathrm{ml}$ of $\mathrm{NaCl} 0.85 \%$ was prepared.

\section{Microbiological analysis}

Immediately after the sampling, serial 10 -fold dilutions were prepared with sterile $\mathrm{NaCl} 0.85 \%(\mathrm{~g} / \mathrm{l})$. The serially diluted cecum content was used for determining the lactic acid bacteria, namely, Lactobacillus spp. and Escherichia coli. The dilution was different $\left(10^{1}-10^{7}\right.$ for Lactobacillus spp. and lactic acid and $10^{1}-10^{4}$ for E. coli). Lactobacillus spp. were cultured on LBS Agar (Lactobacillus selection agar) or Rogosa agar (BD ${ }^{\circledR}$ Europe), E. coli was cultured on MRS agar (BBL ${ }^{\circledR}$, USA), and lactic acid bacteria were cultured on TBX. The plates were incubated at $37^{\circ} \mathrm{C}$ in a GasPak ${ }^{\circledR}$ anaerobic system at $35^{\circ} \mathrm{C}-37^{\circ} \mathrm{C}$ for 24 hours (E. coli) and 48 hours (Lactobacillus spp. and lactic acid bacteria total) (Denou et al., 2016).

\section{Statistical analysis}

The results were subjected to one-way analysis of variance (ANOVA) followed by post hoc the least significant difference tests to analyze the parametrical data, and for nonparametrical data, Mann-Whitney U-tests were used after the Shapiro-Wilk test of normality by Statistical Package for the Social Sciences 23.0 software (IBM Inc., Armonk, NY). The correlation of variables using means and standard deviation (SD) was analyzed by the Pearson and Spearman tests with significance set as $p \leq 0.05$.

\section{RESULTS AND DISCUSSION}

Progressive weight reduction was monitored throughout the treatment period. The body weights at the beginning and the end of 5-week physical exercise and also the weight gains were measured in grams $(\mathrm{g})$. The body weight of the control group $(317.50 \pm 8.92 \mathrm{~g})$ was significantly greater $(p<0.05)$ than that of the MIPE group $(305 \pm 17.46)$ and the HIPE group $(260 \pm 16.73 \mathrm{~g})$ at the end of the 5-week exercise periods. Furthermore, the weight gain was significant in the control group compared to the HIPE group ( $p=0.020)$. In comparison to the MIPE group, the weight gain was not statistically significant. The results of other studies showed that weight loss impacts the gut microbiota composition in mice as well as humans. This is controlled by leptin since this hormone can affect the composition of the intestinal microbiota by stimulating the production of mucin in the intestinal gut (Cao et al., 2005). According to these data, an observation should be conducted about the connection between the intensity of physical exercise and the body weight of rats. As shown in Table 1, it is confirmed that the control group had higher weight gain in comparison to the HIPE group ( $p=0.020)$; however, the weight gain was not statistically significant in comparison to the MIPE group.

Analysis of the cecal samples collected after the rats were allocated into the trained group or the untrained group showed that there were exercise training-induced differences in terms of bacterial diversity. Figures 1 and 2 show the comparison

Table 1. Effect of physical intensity exercise on body weight (mean $\pm \mathrm{SEM}$ ).

\begin{tabular}{ccccc}
\hline & \multicolumn{2}{c}{${\text { Body weight }(\mathbf{g})^{\mathbf{a}}}$} & \multicolumn{2}{c}{ Weight gain $^{\mathbf{a}}$} \\
\hline Group & Week 0 & Week 5 & g & \% week 0 \\
Control & $260 \pm 5.32$ & $317.50 \pm 8.92$ & $57.50 \pm 818$ & $17.93^{\mathrm{a}} \pm 1.84$ \\
MIPE & $253.33 \pm 10.14$ & $305 \pm 17.46$ & $51.67 \pm 32.66$ & $16.21^{\mathrm{a}} \pm 3.44$ \\
HIPE & $246.67 \pm 9.54$ & $260 \pm 16.73^{*}$ & $13.33 \pm 34.45^{*}$ & $3.73^{\mathrm{b}} \pm 5.45$ \\
\hline
\end{tabular}

avalue is mean $\pm \mathrm{SD}(n=5)$.

${ }^{*} p \leq 0.05$ compared to the control group.
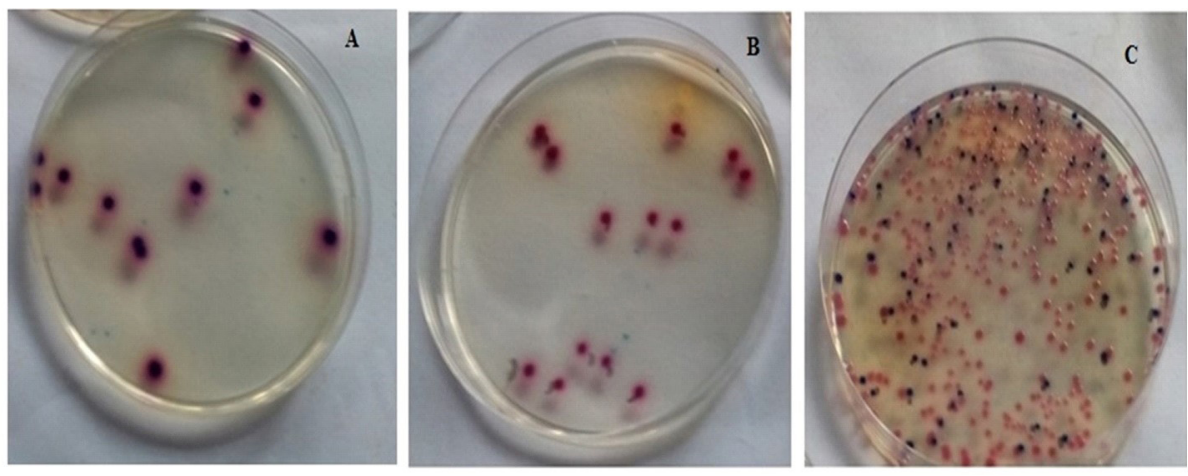

Figure 1. The colony of $E$. coli on TBX media in the control (A), MIPE (B), and HIPE (C) groups. 

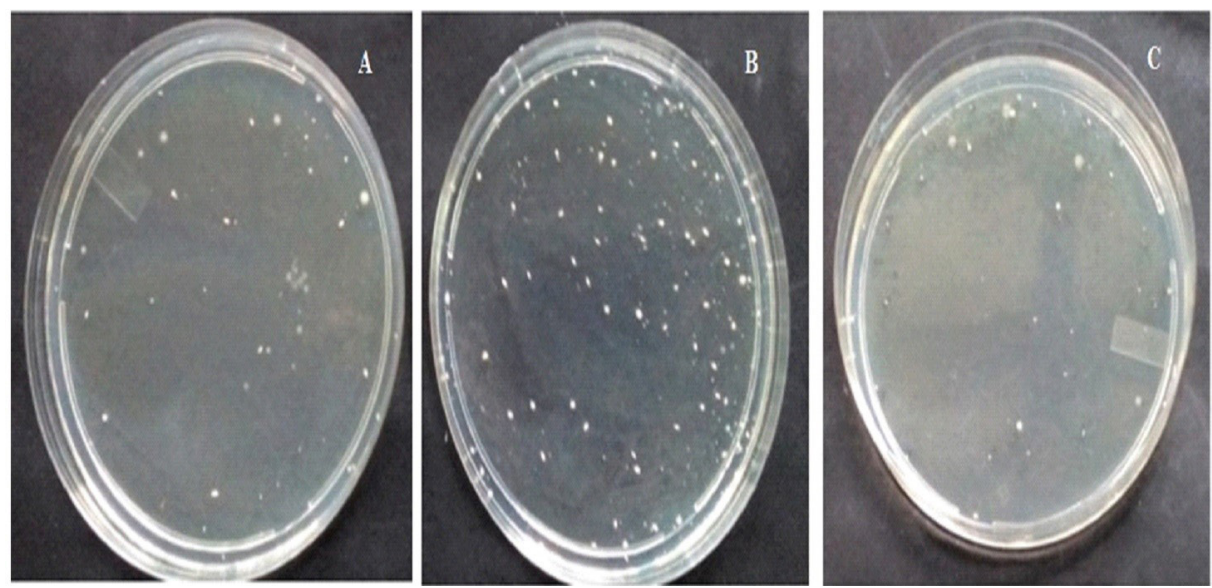

Figure 2. The colony of Lactobacillus spp. in the control (A), MIPE (B), and HIPE (C) groups.
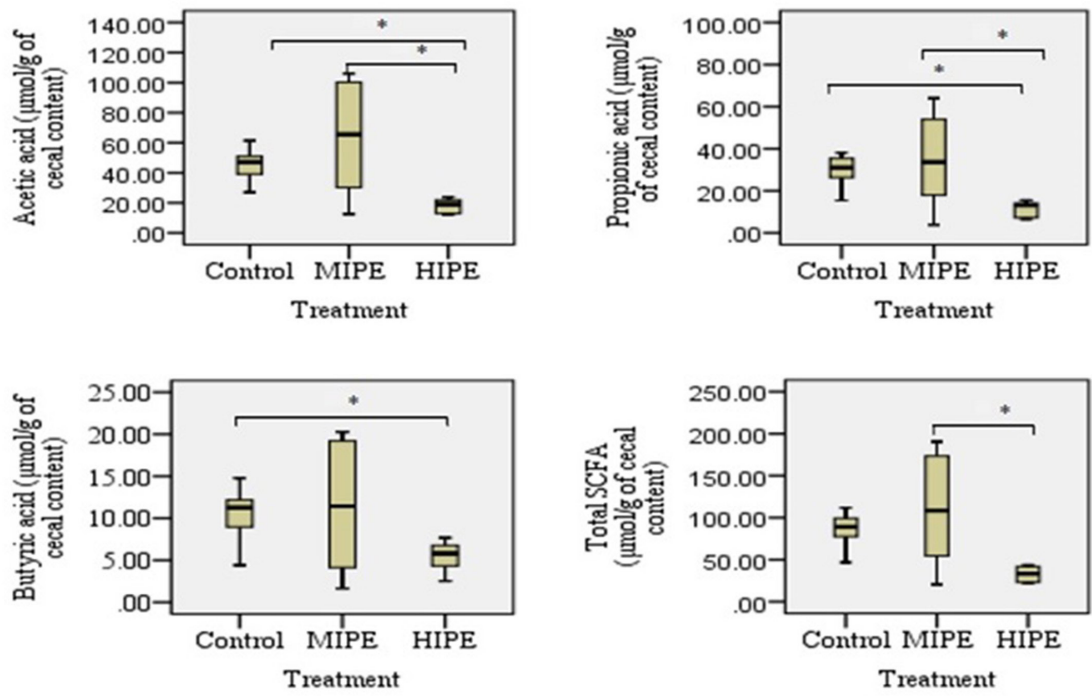

Figure 3. Analysis of fecal (SCFAs) in control, MIPE, and HIPE groups. Bars represent min, median, max, lower, and upper quartile. Statistically, a significant difference between the groups was determined using Mann-Whitney U-test $\left({ }^{*} p \leq 0.05\right)$ for acetic acid, propionic acid, and butyric acid analysis and using post hoc test and one-way ANOVA $\left({ }^{*} p \leq 0.05\right)$ for total short-chain fatty acid (tSCFA) analysis.

between the samples collected from the control group, the MIPE group, and the HIPE group. For specimen comparison, the cecum was collected from the control group, the MIPE group, and the HIPE group. The quantification data and the results of statistical analysis of SCFA components and certain types of bacteria are shown in Figures 3 and 4. There was no significant difference between the SCFA parameters in the control and MIPE groups. From the comparison between the control group and the HIPE group, it was found that acetic, propionic, and butyric acid values were significantly higher $(p=0.04 ; p=0.06$; and $p=0.028$, resp.). Comparison of the control group, the MIPE group, and the HIPE group found that the lactic acid bacteria were higher than Lactobacillus spp. and E. coli, whereas the average counts of lactic acid bacteria were significantly different in each group $(p<0.05)$. The average counts of Lactobacillus spp. in the HIPE group were lower than in the control and MIPE groups (Fig.
4). The results from one-way ANOVA with repeated measures indicated that there was no significant difference $(p>0.05)$ in the Lactobacillus spp. amount in the control, the MIPE, and the HIPE groups. However, the average amounts of E. coli were significantly different $(p<0.05)$ in the MIPE group in comparison to the control and the HIPE groups. Figure 2 shows there were no statistically significant differences in the average amounts of lactic acid bacteria among these groups.

Physical activity has been shown to induce considerable physiological changes in the microbiota composition. However, their relationship to the immune system is still under debate. This study provides evidence that there were differences found in the microbiota composition between the exercised rats and the sedentary rats. Recently, the connection between the alteration of the cecal microbiota environment from exercise and its beneficial effect has emerged and has become a rapidly developing topic. 

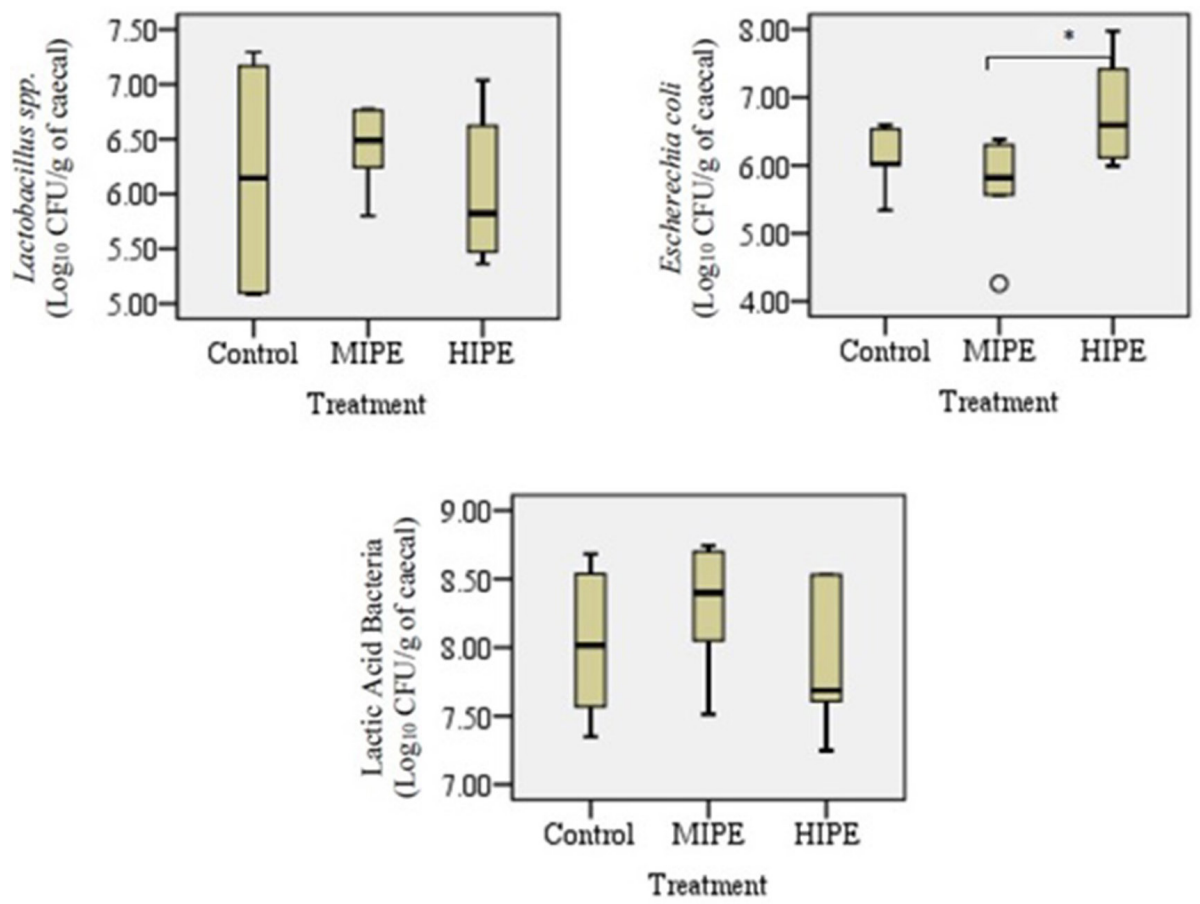

Figure 4. Analysis of selected bacterial in control, MIPE, and HIPE groups. Statistically, a significant difference between the groups was determined using the post hoc test and one-way ANOVA $\left({ }^{*} p \leq 0.05\right)$.

Other studies have also shown that physical exercise alters the intestinal microbiota (El Oufir et al., 1996). The most consistent findings are found from the research on exercise training; the exercise training increased the Bacteroidetes to Firmicutes ratio and also increased the alpha diversity of the microbiota (Cao et al., 2005). Among the rat subjects, the voluntary running exercise determined the variation in the microbiota composition and the increase of n-butyrate concentration (Queipo-Ortuño et al., 2013). In our study, the comparison between the control group, the MIPE group, and the HIPE group did not find any statistically significant difference between the bacterial groups except for $E$. coli between the MIPE and the HIPE groups $(p=0.015)$.

The condition of the crowded cage environment will increase the stress level of the experimental animals which will have an impact on increasing the colonization of $E$. coli in the intestines (Glünder, 2002). Also, the small intestinal dysfunction under physiological stress might be related to the small intestinal motility disorder, the dysbacteriosis, and the damage of mucosa after physiological stress has occurred (Wang and Wu, 2005). The amount of $E$. coli in the proximal intestine of the rats has a significant increase in comparison to the control group (Klaenhammer et al., 2002). As a result, the stress hormone that has been released during the HIPE might also release the catecholamines (norepinephrine, epinephrine, and noradrenaline). In turn, the release of catecholamines might promote the pathogenic E. coli. The present study involved stressful situations because the rats in the HIPE group have undergone HIPEhigh-.

Furthermore, the potential correlations between the SCFAs and the selected bacteria in the untrained rats (the control group) and the trained rats (the MIPE and the HIPE groups) were separately examined. In the control group (Table 1), the SCFA amounts were positively and significantly correlated to the acetic and propionic acid ( $p=0.05$ and $p=0.000$, resp.). Then, in the MIPE group (Table 2), the propionic acid had a positive correlation to acetic and butyric acid and also the tSCFA ( $p=0.05, p=0.005$, and $p=0.000$, resp.). Next, the tSCFAs had a positive correlation to acetic and propionic acid ( $p=0.005$ and $p=0.000$, resp.) followed by butyric acid ( $p=0.005)$. The HIPE group displayed a strong positive correlation between t-SCFA, acetic, and propionic acid (Table 3 ). However, there was a negative correlation between E. coli and all SCFAs. Besides, a negative correlation between lactic acid bacteria and Lactobacillus spp. was found. Last but not the least, a negative correlation $(p=0.050)$ between lactic acid bacteria and SCFA was also found (Table 4).

The Lactobacillus spp. was found to be increased after the exercise was completed including in the control group in comparison to the MIPE group but the comparison result was not statistically different. The increase was associated with the mucosal surface of the small intestines and colon in the subjects which is the place where the subjects produce lactic acid, $\mathrm{CO}_{2}$, acetic acid, and/or ethanol. The reason might be that the lactic acid bacteria in the gastrointestinal tract leads to positive benefits which include a positive influence on the normal microflora, modulation of mucosal immunity, and competitive exclusion of pathogens (Brestenský et al., 2017; Monda et al., 2017). It is observed that the alteration within the selected bacteria is inconsistent across all hosts. It is believed that some of the inconsistent results might be related to the biological differences between each host. In this study, the researchers evaluated the SCFA profile among the control, the MIPE, and the HIPE groups. In the comparison between the control and the HIPE groups, the results showed statistically that the HIPE group had a lower 
Table 2. Correlation between SCFAs and selected bacteria in the control group.

\begin{tabular}{|c|c|c|c|c|c|c|c|c|}
\hline & & $\begin{array}{l}\text { acetic acid } \\
\text { (AA) }\end{array}$ & $\begin{array}{l}\text { propionic } \\
\text { acid (PA) }\end{array}$ & $\begin{array}{c}\text { butyric } \\
\text { acid (BA) }\end{array}$ & tSCFA & $\begin{array}{l}\text { Lactobacillus } \\
\text { spp. (Lb) }\end{array}$ & $\begin{array}{c}\text { lactic acid } \\
\text { bacteria (LAB) }\end{array}$ & $\mathbf{E}$ \\
\hline \multirow[t]{2}{*}{ AA } & $\mathrm{C}$ & & $0.943 * *$ & 0.486 & $0.943 * *$ & -0.257 & -0.371 & 0.232 \\
\hline & $p$ & & 0.005 & 0.329 & 0.005 & 0.623 & 0.468 & 0.658 \\
\hline \multirow[t]{2}{*}{ PA } & $\mathrm{C}$ & $0.943 * *$ & & 0.714 & $1.000^{* *}$ & -0.200 & -0.429 & 0.290 \\
\hline & $p$ & 0.05 & & 0.111 & & 0.704 & 0.397 & 0.577 \\
\hline \multirow[t]{2}{*}{$\mathrm{BA}$} & $\mathrm{C}$ & 0.486 & 0.714 & & 0.714 & -0.371 & -0.486 & 0.087 \\
\hline & $p$ & 0.329 & 0.111 & & 0.111 & 0.468 & 0.329 & 0.870 \\
\hline \multirow[t]{2}{*}{ tSCFA } & $\mathrm{C}$ & $0.943 * *$ & $1.000 * *$ & 0.714 & 1.000 & $-0,200$ & -0.429 & 0.290 \\
\hline & $p$ & 0.005 & & 0.111 & & 0.704 & 0.397 & 0.577 \\
\hline \multirow[t]{2}{*}{$\mathrm{Lb}$} & $\mathrm{C}$ & -0.257 & -0.200 & -0.371 & -0.200 & & 0.714 & 0.319 \\
\hline & $p$ & 0.623 & 0.704 & 0.468 & 0.704 & & 0.111 & 0.538 \\
\hline \multirow[t]{2}{*}{ LAB } & $\mathrm{C}$ & -0.371 & -0.429 & -0.468 & -0.429 & 0.714 & & 0.58 \\
\hline & $p$ & 0.468 & 0.397 & 0.329 & 0.397 & 0.111 & & 0.913 \\
\hline \multirow[t]{2}{*}{ E } & $\mathrm{C}$ & 0.232 & 0.290 & 0.087 & 0.290 & 0.319 & 0.058 & \\
\hline & $p$ & 0.658 & 0.577 & 0.870 & 0.577 & 0.538 & 0.913 & \\
\hline
\end{tabular}

*Significantly different $(p<0.01)$.

**Significantly different $(p<0.05)$

Table 3. Correlation between SCFAs and selected bacteria in the MIPE group.

\begin{tabular}{|c|c|c|c|c|c|c|c|c|}
\hline & & $\mathbf{A A}$ & PA & $\mathbf{B A}$ & tSCFA & Lb & LAB & E. coli \\
\hline \multirow[t]{2}{*}{$\mathrm{AA}$} & $\mathrm{C}$ & & $0.943 * *$ & $0.829 *$ & $0.943 * *$ & 0.371 & -0.600 & 0.600 \\
\hline & $p$ & & 0.005 & 0.042 & 0.005 & 0.468 & 0.208 & 0.208 \\
\hline \multirow[t]{2}{*}{ PA } & $\mathrm{C}$ & $0.943 * *$ & & $0.943 * *$ & $1.000 * *$ & 0.600 & -0.371 & 0.543 \\
\hline & $p$ & 0.05 & & 0.005 & & 0.208 & 0.468 & 0.266 \\
\hline \multirow[t]{2}{*}{$\mathrm{BA}$} & $\mathrm{C}$ & $0.829 *$ & $0.943 * *$ & & $0.943 * *$ & 0.543 & -0.257 & 0.429 \\
\hline & $p$ & 0.042 & 0.005 & & 0.005 & 0.266 & 0.623 & 0.397 \\
\hline \multirow[t]{2}{*}{$\mathrm{tSCFA}$} & $\mathrm{C}$ & $0.943 * *$ & $1.000 * *$ & $0.943 * *$ & & 0.600 & -0.371 & 0.543 \\
\hline & $p$ & 0.005 & & 0.005 & & 0.208 & 0.468 & 0.266 \\
\hline \multirow[t]{2}{*}{$\mathrm{Lb}$} & $\mathrm{C}$ & 0.371 & 0.600 & 0.543 & 0.600 & & 0.257 & 0.429 \\
\hline & $p$ & 0.468 & 0.208 & 0.266 & 0.208 & & 0.623 & 0.397 \\
\hline \multirow[t]{2}{*}{ LAB } & $\mathrm{C}$ & -0.600 & -0.371 & -0.257 & -0.371 & 0.257 & & -0.657 \\
\hline & $p$ & 0.208 & 0.468 & 0.623 & 0.468 & 0.623 & & 0.156 \\
\hline \multirow[t]{2}{*}{ E. coli } & $\mathrm{C}$ & 0.600 & 0.543 & 0.429 & 0.543 & 0.429 & -0.657 & \\
\hline & $p$ & 0.208 & 0.266 & 0.397 & 0.266 & 0.397 & 0.156 & \\
\hline
\end{tabular}

*Significantly different $(p<0.01)$.

**Significantly different $(p<0.05)$.

level of acetic, propionic, and butyric acid than the control group. The production of SCFAs is assumed to be generated by the microbiota and the substrate source. The SCFAs are produced by various bacterial species and through distinct metabolic pathways. A greater content of SCFAs has been ascertained in the cecal contents and the microbiota universe in the cecum is larger and also more varying when compared to the microbiota population in the small intestines. Additionally, the process of fermentation is more concentrated in the cecum. In the present study, it was found that the exercise altered the microbiota population and enhanced the butyric acid concentration in the rats' cecum. Furthermore, butyric acid is shown to be related to endogenous substances such as mucin (Queipo-Ortuño et al., 2013). Both Bifidobacteria and Lactobacillus spp. can produce organic lactic acid, which is converted into butyric acid by butyric acid-producing bacteria in the gut (Brestenský et al., 2017).

A notable observation is found in the HIPE group. There was a negative correlation ( $p=0.050)$ between lactic acid bacteria and SCFAs. The results of another study showed that exercise tends to increase the number of lactic acid bacteria and that there is an association between the mucosal skin of the gastrointestinal area and the yield of lactic acid that has the potency to regulate mucosal resistance and pathogen exclusion (Monda et al., 2017). In the present study, the lactic acid bacteria have a negative 
Table 4. Correlation between SCFAs and selected bacteria in the HIPE group.

\begin{tabular}{|c|c|c|c|c|c|c|c|c|}
\hline & & $\mathbf{A A}$ & PA & BA & tSCFA & Lb & LAB & E. coli \\
\hline \multirow[t]{2}{*}{ AA } & $\mathrm{C}$ & & $0.943 * *$ & -0.200 & $0.829^{*}$ & 0.143 & 0.638 & -0.429 \\
\hline & $p$ & & 0.005 & 0.747 & 0.042 & 0.787 & 0.173 & 0.397 \\
\hline \multirow[t]{2}{*}{ PA } & $\mathrm{C}$ & $0.943 * *$ & & 0.100 & $0.943 * *$ & -0.086 & 0.754 & -0.371 \\
\hline & $p$ & 0.005 & & 0.873 & 0.005 & 0.872 & 0.084 & 0.468 \\
\hline \multirow[t]{2}{*}{$\mathrm{BA}$} & $\mathrm{C}$ & -0.200 & 0.100 & & 0.100 & -0.900 & 0.616 & 0.100 \\
\hline & $p$ & 0.747 & 0.873 & & 0.873 & 0.037 & 0.269 & 0.873 \\
\hline \multirow[t]{2}{*}{ tSCFA } & $\mathrm{C}$ & $0.829 *$ & $0.943 * *$ & 0.100 & & -0.143 & $0.812^{*}$ & -0.257 \\
\hline & $p$ & 0.042 & 0.005 & 0.873 & & 0.787 & 0.50 & 0.623 \\
\hline \multirow[t]{2}{*}{$\mathrm{Lb}$} & $\mathrm{C}$ & 0.143 & -0.86 & $-0.900^{*}$ & -0.143 & & -0.377 & 0.314 \\
\hline & $p$ & 0.787 & 0.872 & 0.037 & 0.787 & & 0.461 & 0.544 \\
\hline \multirow[t]{2}{*}{ LAB } & $\mathrm{C}$ & 0.638 & 0.754 & 0.616 & $0.812^{*}$ & -0.377 & & -0.029 \\
\hline & $p$ & 0.173 & 0.084 & 0.269 & 0.050 & 0.461 & & 0.957 \\
\hline \multirow[t]{2}{*}{ E. coli } & $\mathrm{C}$ & -0.429 & -0.371 & 0.100 & -0.257 & 0.314 & -0.29 & \\
\hline & $p$ & 0.397 & 0.468 & 0.873 & 0.623 & 0.544 & 0.957 & \\
\hline
\end{tabular}

*Significantly different $(p<0.01)$.

**Significantly different $(p<0.05)$.

correlation to the E. coli in the MIPE and the HIPE groups; however, there were no statistically significant differences. The presence of gut microbiota is important for the production of SCFAs in the cecum and the colon, such as butyric, acetic, and propionic acid, which might modulate the host energy balance to increase the nutrients and in general might change SCFAs profile. The mean amounts of acetic acid and propionic acid levels in the MIPE group were significantly higher than in the control and HIPE groups. Meanwhile, the mean amount of butyric acid was significantly lower in the HIPE group than in the control group. This finding is relevant to the results of previous studies (Monda et al., 2017; Shirayama et al., 2002); that is, (1) exercise can improve the microflora variety, (2) changes in the BacteroidetesFirmicutes ratio can potentially play a role in weight loss; (3) the bacterial proliferation can help regulate mucosal resistance, and (4) improve barrier functions that result in stimulation of bacteria able to produce SCFAs. These SCFAs affect lipid, glucose, and cholesterol metabolism in various tissues and the maintenance of gut integrity. These might be possible mechanisms for increasing muscle mass and strength. As a result, Lactobacillus spp. had a negative correlation to the acetic, propionic, and butyric acid followed by tSCFAs in the control group and the MIPE group. Similarly, E. coli had a negative correlation to Lactobacillus spp. in the MIPE group. However, there were no statistically significant differences found and thus, the findings do not support the premise that Lactobacillus spp. is responsible for the increase of SCFAs synthesis.

These findings indicate that physical exercise can change the balance of intestinal microbiota which are critical in the avoidance of bacterial pathogens. This connection supports how the moderate intensity of physical exercise might contribute to better well-being of the microbiota environment as demonstrated by an essentially higher sum of acidic and propionic production; however, the contribution did not appear within the high-intensity exercise.

\section{CONCLUSION}

Moderate intensity of exercise may contribute to the better well-being of the microbiota environment as shown by the significantly higher acetic and propionic acid production but not in the high-intensity exercise group.

\section{AUTHOR CONTRIBUTION}

Andreanyta Meliala and Titik Nuryastuti contributed to the conception and design of the study. Paramita Narwidina and Hera Nirwati contributed to data acquisition and data interpretation while Titik Nuryastuti organized drafting the manuscript with Laode Ardiansyah, Muhammad Kamil, and Arso Pranindyo. All authors have approved the final manuscript.

\section{ACKNOWLEDGMENTS}

The authors would like to show their gratitude to the contributing laboratory staff of the Physiology, Medicine Faculty of Universitas Gadjah Mada, for their assistance during the study. The researchers also thank the grant of 2017 Public Funds (Hibah Dana Masyarakat) from the Faculty of Medicine, Public Health and Nursing, Universitas Gadjah Mada, Yogyakarta, Indonesia, so that the study might be conducted well.

\section{CONFLICT OF INTEREST}

The authors declare that there is no conflict of interest related to this study.

\section{FUNDING}

All of the authors report that there is no financial or personal relationship with other people or institutions that might influence their conduct.

\section{ETHICAL APPROVALS}

This study does not involve experiments on animals or human subjects. 


\section{REFERENCES}

Brestenský M, Nitrayová S, Bomba A, Patráš P, Strojný L, Szabadošová V, Pramuková B, Bertková I. The content of short-chain fatty acids in the jejunal digesta, caecal digesta, and feces of growing pigs. Livest Sci, 2017; 205(2):106-10.

Brooks G, White T. Determination of metabolic and heart rate responses of rats to treadmill exercise. J Appl Physiol Respir Environ Exerc Physiol, 1979; 45:1009-15.

Cao SG, Xia XP, Wang WX, Zheng JJ, Xue ZX. Effects of psychological stress on small intestinal motility, somatostatin, and substance P levels in plasma and small intestine in mice. World Chin J Dig, 2005; 13(8):967-70.

Denou E, Marcinko K, Surette MG, Steinberg GR, Schertzer JD. High-intensity exercise training increases the diversity and metabolic capacity of the mouse distal gut microbiota during diet-induced obesity. Am J Physiol Endocrinol Metab, 2016; 310(11):E982-93.

El Oufir L, Flourié B, Bruley des Varannes S, Barry JL, Cloarec D, Bornet F, Galmiche JP. Relations between transit time, fermentation products, and hydrogen consuming flora in healthy humans. Gut, 1996; 38(6):870-7.

Finegold, Sydney M, Vera L. Sutter, Glenn E. Mathisen. Normal indigenous intestinal flora. In Hentges DJ (ed.). Human intestinal microflora in health and disease. Academic Press, Inc., New York, pp 3-31, 1983.

Glünder G. Influence of diet on the occurrence of some bacteria in the intestinal flora of wild and pet birds. Dtsch Tierarztl Wochenschr, 2002; 109:266-70.

Hart BL. Behavioral adaptations to pathogens and parasites: five strategies. Neurosci Biobehav Rev, 1990; 14(2):273-94.

Hijova E, Chmelarova A. Short-chain fatty acids and colonic health. Bratisl Lek Listy, 2007; 108(8):54-8.

Klaenhammer T, Altermann E, Arigoni F, Bolotin A, Breidt F, Broadbent J, Cano R, Chaillou S, Deutscher J, Gasson M, van de Guchte M, Guzzo J, Hartke A, Hawkins T, Hols P, Hutkins R, Kleerebezem M, Kok J, Kuipers O, Lubbers M, Maguin E, McKay L, Mills D, Nauta A, Overbeek R, Pel H, Pridmore D, Saier M, van Sinderen D, Sorokin A, Steele J, O'Sullivan D, de Vos W, Weimer B, Zagorec M, Siezen R. Discovering lactic acid bacteria by genomics. Antonie van Leeuwenhoek, 2002; 82(14):29-58.

Matsumoto $\mathrm{M}$, Inoue $\mathrm{R}$, Tsukahara $\mathrm{T}$, Ushida $\mathrm{K}$, Chiji $\mathrm{H}$, Matsubara N, Hara H. Voluntary running exercise alters microbiota composition and increases n-butyrate concentration in the rat cecum. Biosci Biotechnol Biochem, 2008; 72(2):572-6.
Monda V, Villano I, Messina A, Valenzano A, Esposito T, Moscatelli F, Viggiano A, Cibelli G, Chieffi S, Monda M, Messina G. Exercise modifies the gut microbiota with positive health effects. Oxid Med Cell Longev, 2017; 2017:3831-972,

Nieman D, Wentz L. The compelling link between physical activity and the body's defense system. J Sports Heal Sci, 2019; 8:201-17.

O'Hara AM, Shanahan F. The gut flora as a forgotten organ. EMBO Rep, 2006; 7(7):688-93.

Picard C. Review article: Bifidobacteria as probiotic agents biological effects and clinical benefits. Aliment Pharmacol Ther, 2005; 22:495-512.

Queipo-Ortuño MI, Seoane LM, Murri M, Pardo M, GomezZumaquero JM, Cardona F, Casanueva F, Tinahones FJ. Gut microbiota composition in male rat models under different nutritional status and physical activity and its association with serum leptin and ghrelin levels. PLoS One, 2013; 28;8(5):e65465.

Russell WR, Hoyles L, Flint HJ, Dumas ME. Colonic bacteria metabolites and human health. Curr Opin Microbiol, 2013; 16(3):246-54.

Sekirov I, Russell SL, Antunes LCM, Finlay BB. Gut microbiota in health and disease. Physiol Rev, 2010; 90(3):859-904.

Shirayama Y, Chen ACH, Nakagawa S, Russell DS, Duman RS. Brain-derived neurotrophic factor produces antidepressant effects in behavioral models of depression. J Neurosci, 2002; 22(8):3251-61.

Sohail MU, Yassine H, Sohail A, Thani A. Impact of physical exercise on gut microbiome, inflammation, and the pathobiology of metabolic disorders. Rev Diabet Stud, 2019; 15:35-48

Wang SX, Wu WC. Effects of psychological stress on small intestinal motility and bacteria and mucosa in mice. World J Gastroenterol, 2005; 11(13):2016-21.

Yousefi MR, Bakhtiyari S. Reviewing and comparing the impact of aerobic exercise ( 3 and 5 times per week) on insulin receptors, glucose transporter protein (GLUT4), and skeletal muscle insulin sensitivity in diabetic rats. J Appl Pharm Sci, 2017; 7(2):132-6.

\section{How to cite this article:}

Meliala A, Narwidina P, Nirwati H, Nuryastuti T, Kamil M, Ardiansyah L, Pranindyo A. The impact of moderate- and high-intensity exercise on microbiota population and shortchain fatty acid production in the cecum of rats. J Appl Pharm Sci, 2021; 11(08):090-097. 